\title{
Food or host: do physiological state and flower type affect foraging decisions of parasitoids?
}

Maxime Damien ${ }^{1,2, *}$, Léna Barascou ${ }^{1,3}$, Aurélien Ridel ${ }^{1}$, Joan Van Baaren ${ }^{1}$ and Cécile Le Lann $^{1}$

(1) Université de Rennes 1, UMR CNRS 6553 Ecobio, 263 Avenue du Gal Leclerc, CS 74205, 35042 Rennes Cedex, France

(2) Institut Sophia Agrobiotech [Sophia Antipolis] (ISA) - Institut national de la recherche agronomique (INRA) : UMR1355, Université Nice Sophia Antipolis (UNS), CNRS : UMR7254 - INRA Centre de recherche Provence-Alpes-Côte d'Azur, 400 route des Chappes, BP 167, 06903 Sophia Antipolis Cedex, France

(3) INRA, UMR 406 Abeilles et Environnement, UMT Protection des Abeilles dans l'Environnement, Domaine Saint-Paul, 84914 Avignon, France

\section{lena.barascou@inra.fr}

aurelien.ridel@etudiant.univ-rennes1.fr

joan.van-baaren@univ-rennes1.fr

cecile.lelann@univ-rennes1.fr

\section{Correspondance: $\quad(*)$ maximedamien15@gmail.com}

Maxime DAMIEN, ORCID : 0000-0002-3553-5182. Current adress: Crop Research Institute, Drnovska 507, 16106 Praha 6 - Ruzyne, CZECH REPUBLIC. +420 775115539

Conflict of Interest: The authors declare that they have no conflict of interest.

\section{Acknowledgments}

The authors would like to thank Sandra Rigaud, Bertrand Di Cesare and Valérie Briand for support in administrative tasks, Valérie Briand again for her help in processing the bibliographic database, Aziliz Le Rouzo for proofreading the manuscript and finally both editor and anonymous reviewer for their insightful comments. The FLEUR project (ONEMA) and the French National Institute for Agricultural Research (INRA, SPE department) funded this research and Maxime Damien's grant. This is a post-peer-review, pre-copyedit version of an article published in Behavioral Ecology and Sociobiology. The final authenticated version is available online at: http://dx.doi.org/10.1007/s00265-019-2758-9

Keywords: Behavioral choices, Food quality and attractiveness, Life expectancy, Mating, Optimal foraging theory, Parasitoid 
1 Abstract: Within the Optimal Foraging Theory framework, parasitoids constitute ideal models to

2 elucidate combined physiological and environmental determinism of foraging behavior between current

3 and future fitness gains. Parasitoid females need hosts to lay eggs for their reproduction (immediate

4 gain), but also sugar food resources for their survival (future gain). According to theoretical models and

5 previous empirical studies, fed females should favor host foraging, whereas females with lower

6 energetic reserves should search for food. Surprisingly, the influence of mating status and food quality

7 has not been considered, whereas they may both constitute major factors altering animals' choices

8 between reproducing and feeding. We tested decision-making on Aphidius rhopalosiphi parasitoid

9 females with different life expectancy levels (as set by recent feeding history) and mating status, using

10 two flower species with contrasted attractiveness and nectar suitability. Interestingly, all fed and unfed

11 females with different expected lifetime levels favored reproduction over nutrition since they are mated.

12 This could be explained by their reproductive status that appeared to be the main determinant of their

13 foraging decisions. For a given expected lifetime, mated females favored more reproduction whereas

14 unmated ones favored food. Interestingly, physiological status of females (mating and lifetime expectancy) did not interact with flower species on their foraging decisions nor did it modify their preferences, as they always favored the most attractive flower, which does not have the best nectar.

17 These results highlight the need for more empirical studies to evaluate the interactions between different intrinsic factors and to carefully consider the mating status in model assumptions, as it influences foraging behavior between immediate and future fitness gains.

21 Significance Statement: Parasitic wasps need hosts to lay eggs for their reproduction (immediate 22 fitness gain) and sugar resources for their survival (future fitness gain). Empirical studies and related theoretical models about foraging decisions of parasitic wasps between current and future gains included influences of energetic and resource availability constrains. We examined assumptions used by those mathematical models by empirically testing two new factors, food qualities provided by two nectar provisioning flower species with contrasted functional traits, which had surprisingly no impact on decision-making, and mating status which we showed to play a decisive role on decision-making between food or host resources. These factors should henceforth be considered in model assumptions or in models themselves to realize accurate predictions and to provide a better understanding of

30 foraging decisions made by female parasitic wasps. 


\section{Introduction}

Life reproductive success of organisms (i.e., fitness, the net contribution to the next generation) is limited by time and nutrients (de Jong and van Noordwijk 1992; Tatar and Carey 1995) resulting in a trade-off between current reproduction (i.e., immediate fitness gains) and survival (i.e., future fitness gains) (Stearns 1976; Roff 2002; Bernstein and Jervis 2008). Due to limited intrinsic energetic reserves (Morano et al. 2013) and to external biotic and abiotic constraints (Török et al. 2004; Killen et al. 2013; Stienen et al. 2015), organisms modulate their resource allocation between life history traits, such as fecundity and longevity. This plasticity in energy allocation occurs mainly by changes in foraging behaviors adopted by individuals (Wolf et al. 2007), either looking for resources that could increase their current reproductive success (e.g. breeding sites, sexual partners, offspring care, etc.) or those that could increase their expected lifespan (e.g. shelters decreasing predation risks, food supplies, etc.). In this context, fitness optimization for an organism depends on the elaboration of optimal foraging decisions (Pyke 1984; Tatar and Carey 1995).

The Optimal Foraging Theory (OFT) was developed to predict the optimal decision-making of animals looking for food, like predators foraging for prey, in order to maximize their fitness at low mortality risks and energetic costs (Townsend and Hildrew 1980; Lacher et al. 1982). Parasitoid insects (i.e. arthropods that need another living organism as host for their reproduction) have been extensively studied within the OFT framework (Bernstein \& Jervis, 2008; Wajnberg, 2006). Indeed, parasitoid females need hosts (i.e. other arthropods) for their reproduction (Godfray, 1994), but also sugar resources for their survival as adults (Azzouz et al. 2004; Lee et al. 2006; Tena et al. 2015). Adults of many parasitoids species are unable to feed on their hosts and sugars are mainly found in the honeydew of phloem consumers (Fischbein et al. 2016) or in floral nectar (Winkler et al. 2009). When insect hosts produce honeydew, parasitoid females may find hosts and food at the same location. However, the energetic benefits of honeydew are lower than those obtained by feeding on some flower nectar (Lee et al. 2004; Tena et al. 2018), and parasitoids that experienced nectar prefer this food resource rather than honeydew (Vollhardt et al. 2010). Consequently, as oviposition and feeding sites are often separated in 
space, parasitoid females need to optimize costly movements between these different discrete patches (Van Alphen and Vet, 1986; Hassell and Southwood, 1978; Jervis et al., 1993).

Within OFT conceptual framework, predictions of optimal decision-making by parasitoids between foraging for hosts or food have been improved by the use of stochastic dynamic models (Clark and Mangel 2000). Both SB (Sirot and Bernstein 1996) and TSK (Tenhumberg et al., 2006) mathematical models predict that well-fed female parasitoids should always search for hosts whereas they should search for food only when they are close to die from starvation. However, the two models differ in their assumptions. The SB model is considering that decision-making is based on the interaction between the energetic state of the female parasitoid and the resource availability. Therefore, in the SB model, females should favor food foraging when they are starving and only when food is available and abundant. By contrast, in the TSK model, food foraging by females is assumed to be independent of the probability of finding food as well as of its quantity or quality. These model predictions strictly based on the energetic status of individuals were supported by a few empirical studies prior to their development (Roitberg et al. 1992; Wäckers 1994; Jacob and Evans 2001; Siekmann et al. 2004). Additionally, the study conducted by Lucchetta et al. (2007) supported the assumption of the SB model, showing that the tendency of females of the parasitoid Venturia canescens to leave a reproductive patch was mediated by both metabolic reserves and food availability in the vicinity. Nevertheless, the impact of other environmental and intrinsic factors on the decision to search for hosts or food still remains to be explored.

Factors affecting food foraging by female parasitoids in species that do not host-feed have received little attention, with most focus on preferences among plant species bearing nectar (Russell 2015) and always as an alternative to the host foraging behavior. In contrast, several physiological parameters are known to influence host foraging behaviour. These parameters includes the expected lifespan, the number of mature eggs available or the mating status (Minkenberg et al. 1992; Heimpel and Collier 1996; Fauvergue et al. 1999; Jacob and Evans 2001). So far, only the energetic status or associated lifetime expectancy of female parasitoids has been considered on host $v s$ food foraging decisionmaking. However, mating status is known to modify foraging behavior in several groups of organisms 
(Reaney 2007; Wexler et al. 2017). For parasitoids, haplodiploidy results in females producing only males when unmated versus both sexes when mated, and therefore mating status may also constitute a determinant intrinsic factor of their foraging decisions (Fauvergue et al. 2008; Kant et al. 2012). For instance, it has been shown that mated females of Monoctonus paulensis (Hymenoptera; Braconidae) are more predisposed to reproduce and stay longer on host patches than unmated ones when foraging for hosts (Michaud and Mackauer 1995). Consequently, the potential influence of female parasitoid mating status on their foraging decisions within the trade-off between current or future fitness gains remains to be studied.

Additionally, host foraging behavior is also known for being mediated by extrinsic abiotic conditions such as temperature or precipitation (Fink \& Völkl, 1995; Le Lann, Outreman, van Alphen, \& van Baaren, 2011), as well as by biotic factors, as for instance the presence of competitors (Martinou, Milonas, \& Wright, 2009; van Baaren, Outreman, \& Boivin, 2005; Wang \& Keller, 2005). Among these extrinsic factors, food quality and quantity are the focus of the SB and TSK models. However, the influence of both food quality and attractiveness provided by flowering plants on foraging decision, as well as potential interactions with other physiological parameters than the energetic state of females remain unknown. Better understanding of parasitoid decision-making between feeding and reproducing is thus needed to improve both model predictions and biological control programs using parasitoid insects.

The current study aimed to test the influence of intrinsic physiological factors (life expectancy as a proxy of their energetic reserves (Snart et al. 2018), and mating status), as well as extrinsic factors (nectar suitability and flower attractiveness) on the foraging decisions between food and hosts of parasitoid females Aphidius rhopalosiphi (Hymenoptera: Braconidae). This parasitoid species is dominant within aphid-parasitoid community of cereal crops from western part of France, and benefits from cultivated flowering plants used in agricultural landscape (Damien et al. 2017). We also examined if these physiological states influenced their flower preferences. The following hypotheses were tested: (1) for given flower species and mating status, female parasitoids with high life expectancy levels (i.e. high energetic reserves) should favor immediate fitness by choosing host patches whereas females with 
111 intermediate and low life expectancy levels (i.e. lower energetic reserves) should favor future fitness

112 by choosing food patches. (2) For a given flower species and a given a life expectancy status, unmated

113 females may choose to feed whereas mated ones may choose to oviposit. (3) Finally, the quality of the

114 flower nectar or the attractiveness of the flower may. Finally, the quality of the flower nectar or the

115 attractiveness of the flower may modify female preferences for the flower species used as food patch,

116 by interacting with the internal state of female wasps, ultimately influencing the decision-making

117 between foraging for hosts and for food. In particular, females with low life expectancy may be expected

118 to choose more often to feed on the most suitable flower nectar (i.e. increasing their longevity) or on

119 flowers that are highly attractive (e.g. preferences for particular flower colors and/or odors).

\section{Materials and methods}

\section{$121 \quad$ Flowering plants}

122 Two different flowers species that are currently encountered in agricultural landscapes of western

123 France were tested as nectar food resource: the buckwheat (Fagopyrum esculentum, var KORA,

124 Polygonaceae) and the white mustard (Sinapis alba, var SIGNAL, Brassicaceae). Seeds, provided by 125 the SA Pinault company were sown in trays $(20 \times 15 \times 5 \mathrm{~cm})$ and placed into controlled conditions $126\left(20^{\circ} \mathrm{C}, 70 \pm 10 \% \mathrm{RH}, 16 \mathrm{~L}: 8 \mathrm{D}\right.$ photoperiod). After two weeks, seedlings were transplanted into 127 individual pots $(7 \times 7 \times 8 \mathrm{~cm})$ and grown under the same conditions for two more weeks. Then, seedlings 128 were transferred into larger pots $(h=17 \mathrm{~cm}, \varnothing=7 \mathrm{~cm})$ in a greenhouse until they flowered and were 129 used in experiments. Buckwheat flowers have a highly suitable "sucrose dominant" nectar that increases

130 fitness of several parasitoids species including A. rhopalosiphi (Vattala et al. 2006; Irvin et al. 2014;

131 Damien 2018), but are considered to be poorly attractive flowers for parasitoids (Russell 2015). By 132 contrast, white mustard flowers are highly attractive for many species (Russell, 2015), such as observed

133 in A. rhopalosiphi but have a nectar of poor quality, known as "hexose dominant" nectar (Vattala et al.

134 2006; Tompkins et al. 2010; Damien 2018). 
137 Both parasitoids and aphids were collected between 2014 and 2015 in cereal crops in the Zone Atelier

138 Armorique (https://osur.univ-rennes1.fr/za-armorique) near Rennes (France). The parasitoid Aphidius

139 rhopalosiphi (Hymenoptera, Braconidae) was reared in the laboratory on a mixed-aged culture of the

140 aphid Metopolophium dirhodum (Hemiptera, Aphididae). Parasitoid cultures were annually supplied

141 with individuals from the field to improve genetic diversity within rearing. This parasitoid species is

142 unable to feed on the hemolymph of its host and honeydew is expected to constitute a poorly energetic

143 resource (Lee et al. 2004; Tena et al. 2018). Without feeding, A. rhopalosiphi individuals have a low

144 life expectancy that does not exceed two or three days under controlled conditions (Le Lann 2009).

145 Aphids were reared on organic winter wheat plants (Triticum aestivum, cultivar Ludwig) provided by

146 the SA Pinault company. Both aphids and parasitoids were maintained in Plexiglas cages $(50 \times 50 \times 50$

$147 \mathrm{~cm})$ under controlled conditions $\left(20^{\circ} \mathrm{C}, 70 \pm 10 \% \mathrm{RH}\right.$, photoperiod de $\left.16 \mathrm{~L}: 8 \mathrm{D}\right)$. To obtain standardized

148 parasitoid individuals for experiments, mummies (dead aphids containing nymphs of parasitoids) were

149 collected from the culture and placed individually in gelatin capsules $(\mathrm{L}=2 \mathrm{~cm}, \varnothing=0.7 \mathrm{~cm})$ until adult

150 emergence. Emergences were checked twice a day, and females that had emerged within the past twelve

151 hours were then assigned to different feeding and mating treatments before being used in the

152 experiments.

153 Mated females with three different intrinsic expected lifetimes (i.e. energetic status)

154 Three different levels of expected lifetime (low, intermediate and high) were tested. To obtain females

155 with low and high life expectancy, each newly emerged female was enclosed during the first $24 \mathrm{~h}$ of the 156 experiment under controlled conditions $\left(20^{\circ} \mathrm{C}, 70 \pm 10 \% \mathrm{RH}\right.$, photoperiod de $\left.16 \mathrm{~L}: 8 \mathrm{D}\right)$ in plastic tubes $157(\varnothing=1.4 \mathrm{~cm} ; \mathrm{L}=16 \mathrm{~cm})$ with ad libitum water access and two males for mating (Le Lann, Roux, et al.,

158 2011; Le Lann, Wardziak, van Baaren, \& van Alphen, 2011). Seventy five percent of mating occur 159 within 30 min in Aphidius parasitoids and all females are assumed to be mated after being enclosed 160 with males during 24h (Levie et al. 2005; McClure et al. 2007; Bourdais and Hance 2009). During this $16124 \mathrm{~h}$ period, females were placed either without food (low expected lifetime, close to death due to 162 starvation, $\mathrm{N}=25$ ), or with droplets of honey (high expected lifetime, $\mathrm{N}=20$ ). To obtain females with 
163 "intermediate" life expectancy $(\mathrm{N}=25)$, newly emerged females were individually enclosed in

164 Eppendorf tubes with two males, ad libitum water access but no food, and all females were tested in the

165 next 4 hours after mating occurred. These three groups of females were tested in a choice situation

166 between one host patch (aphids) and one food patch (see Experimental design for behavioral

167 choices').

168 Intermediate expected lifetime females with different mating status

169 In order to assess the effect of the mating status, as all trials are independent from each other, it was

170 assigned to the 'mated females' group $(\mathrm{N}=25)$ the mated females with intermediate lifetime from

171 previous comparison of low, intermediate, and high expected lifetimes. The data was completed with

172 new trials using newly emerged females that were placed in Eppendorf tubes with one to two virgin

173 males that were less than 48h-old and observed for 30 minutes, without food access but with water $a d$

174 libitum. Females that did not mate during this time were assigned to the 'unmated females' group $(\mathrm{N}=$

175 28). These females were unfed and tested in the next 4 hours after mating that corresponds to the

176 intermediate expected lifetime, as defined in the previous experiment. These two groups of females

177 were tested in a choice situation between one host and one food patch (see 'Experimental design for

178 behavioral choices').

179 An absence of mating after 30 minutes decided in the protocol may result from several drivers (like

180 physiological incompatibility, kinship or diploid males linked to the rearing conditions (Werren and

181 Loehlin 2009)), that could ultimately influence female decision-making between hosts and food. To

182 take into account the potential effect of male encountering on decision-making in the 'unmated females'

183 group, a third group $(\mathrm{N}=15)$ with unmated females that never encountered males was also tested in

184 presence of mustard flower as a food patch. Given the choice between hosts or flower, decision-making

185 only significantly differed between mated and both types of unmated females (GLMM: $\chi^{2}=11.09$, df=

$1862, \mathrm{p}<0.01)$ whereas unmated females that encountered a male or not present similar proportions in their

187 patch choice $(|z|=0.82, p=0.69)$. Consequently, further trials with buckwheat flower and all analyses

188 were only conducted with mated females and the unmated ones that encountered males for 30 min but 189 did not mate. 
191 To establish if flower species were chosen more often by A. rhopalosiphi females according to their

192 nectar value or because of their attractiveness, we investigated A. rhopalosiphi preferences for the two

193 flowers (buckwheat or mustard) in a choice test. Females with different mating status and expected

194 lifetime (i.e. mated or unmated with low or intermediate life expectancy, both as defined above) were

195 offered to choose between two food patches constituted by mustard and buckwheat flowers (see

196 'Experimental design for behavioral choices'). Female from the high life expectancy group were not

197 used in this experiment as all of them favored the host patch (see result section).

\section{Experimental design for behavioral choices}

199 To assess the effects of flower species and different physiological conditions of females, as well as the

200 potential interactions between those factors, on their foraging decision-making between hosts and food,

201 the two flowers species were tested as food patches. The food patch was then constituted of one freshly

202 cut inflorescence of buckwheat or mustard. The host patch was constituted of a wheat plantlet $(\sim 6 \mathrm{~cm}$

203 high, same variety and same growing conditions as explained above), infested 30 minutes before trials with 10 second-third instars of $M$. dirhodum aphids. This aphid density is commonly encountered in the

205 field (Dedryver 1987) and these instars are preferred by parasitoids (Outreman et al. 2005). During trials, stems of inflorescences and wheat plantlets were placed in water to avoid plant wilting.

207 For each treatment (different expected lifetime and mating status) and flower species (buckwheat and

208 white mustard) described above, the foraging behavior of individual females was observed in a 209 Plexiglas cage $(28 \times 15 \times 16 \mathrm{~cm})$ under homogeneous white light. The female was delicately released 210 from an Eppendorf tube at the center of the cage on an introduction patch constituted of a $6 \mathrm{~cm}$ high

211 plastic rod. At five centimeters on each side of the introduction patch were placed one host patch and 212 one food patch (or two food patches with two different flowers in the last experiment). The behavioral 213 patterns of each female were recorded by focal sampling, using the "SequenceR" plugin in the R 214 software (Herve, 2013). Recording started when the female was deposited on the introduction patch. 215 Recording stopped when the female stayed immobile on the last visited patch or remained outside the 
216 last visited one for more than ten minutes. Almost $70 \%$ of the females tested met these criteria after

217 visiting only one patch, and more than $60 \%$ of the $30 \%$ of females that performed more than one visit

218 did it on the same patch that they chose first. Consequently, the study is focused principally on the first

219 choice and associated behavior adopted by newly emerged females. Recorded behavioral items

220 included: entering and leaving a patch (host or food patch), stinging a host or feeding on the flower

221 nectar. The latency for choosing a patch, the type of patch chosen (host or food and mustard or

222 buckwheat flowers in the respective experiments) were measured, as well as the patch time residency

223 during each visit realized prior to meet the ten minutes criterion ending the trial. The latency for

224 choosing a patch was defined as the duration between entering the introduction patch and entering the

225 chosen patch. The patch residence time was defined as the total time between entering and leaving the

226 patch for each visit.

\section{Statistical analyses}

228 To compare the effects of the life expectancy level or of the mating status on their choice between ovipositing and feeding, as well as on their preferences between mustard and buckwheat flowers

230 species, three independent GLMs were performed. In each model, the response variable tested was the

231 proportion of females choosing each patch (host or food in the two first cases, mustard or buckwheat

232 flower in the last one), using binomial errors and logit functions. Fixed effects included physiological

233 states ("low", "intermediate" and "high" life expectancy of mated females in a first GLM, mated and

234 unmated females with intermediate life expectancy in the second one) and flower species (mustard and

235 buckwheat). For the third GLM, life expectancy and mating status were tested as fixed effects on the

236 flower preferences of parasitoid females. For each of the three situations, decision-making duration and

237 patch time residency were also compared using Cox proportional hazards models distribution

238 (Wajnberg, Fauvergue, \& Pons, 2000). Fixed effects were the same as previously described but the

239 chosen patch was also added as a qualitative co-variate in these models. Finally, the number of feeding

240 occurrence and the number of attacked aphids, according to females' choices between host and food

241 patches, were compared by performing GLMs with a Poisson distribution using log functions. Type 3

242 ANOVAs were performed on each model sets with all interactions between fixed effects. Models were 
243 simplified by sequentially removing non-significant interactions, starting with the least significant

244 highest order interaction and all fixed effects were kept in final models (Zuur et al. 2009). When

245 singularity was observed between fixed effects, interaction terms involved were manually removed

246 from the model until being valuable for analyses. ANOVA' assumptions were assessed prior to each

247 test, by checking variance homogeneity and normal distribution of the residuals for LMs, or by using

248 DHRMA package for GLMs (Hartig 2018).

\section{Results}

Effects of the expected lifetime and the flower species on the foraging behavior of mated

\section{females}

There was no significant interaction between life expectancy levels and flower species on foraging decision $\left(\chi^{2}=2.14, \mathrm{df}=2, \mathrm{p}=0.34\right)$. Decision-making of females differed according to their expected lifetime levels (chosen patch: $\chi^{2}=14.86, \mathrm{df}=2, \mathrm{p}<0.001$ ). Females with the highest life expectancy (i.e., honey-fed) always chose to reproduce whereas unfed ones with intermediate and low expected lifetime were more prone to choose the food patch, even though in proportion they also chose more often the host patch (Fig 1-A). Time for decision-making did not vary according to the expected lifetime of females $\left(\chi^{2}=0.23, \mathrm{df}=2, \mathrm{p}=0.89\right)$ whereas time residency on the chosen patch $\operatorname{did}\left(\chi^{2}=9.31, \mathrm{df}=2\right.$, $\mathrm{p}<0.01)$. Females with the highest life expectancy level stayed longer $(24.08 \min \pm 2.98$; mean \pm SE $)$ than the ones with intermediate or lower expected lifetime (respectively $10.98 \pm 1.73$ and $12.50 \pm 3.79$ ). Both foraging decisions and behaviors did not change according to the flower species that constituted

262 the food patch (patch chosen: $\chi^{2}=0.017, \mathrm{df}=1, \mathrm{p}=0.9$; latency before decision-making: $\chi^{2}=0.43$, $\mathrm{df}=1$, $263 \mathrm{p}=0.51$; patch time residency: $\chi^{2}=0.81, \mathrm{df}=1, \mathrm{p}=0.37$ ). The number of feeding behaviors for females 264 that chose the food patch did not vary among expected lifetime $\left(\chi^{2}=1.69, \mathrm{df}=2, \mathrm{p}=0.13\right)$, nor between flower species $\left(\chi^{2}=1.078 \mathrm{df}=2, \mathrm{p}=0.22\right)$ and the interaction was not significant $\left(\chi^{2}=12.75, \mathrm{df}=1, \mathrm{p}\right.$ $=0.062$ ). For females that chose the host patch, there was no significant interaction between life expectancy levels and flower species fixed effects on the number of aphid attacks $\left(\chi^{2}=2.8, \mathrm{df}=1, \mathrm{p}\right.$ $=0.087)$ nor an effect of flower type that constituted the associated food patch $\left(\chi^{2}=1.69, \mathrm{df}=2, \mathrm{p}=0.13\right)$.

However there were significantly $\left(\chi^{2}=9.31, \mathrm{df}=2, \mathrm{p}<0.01\right)$ more aphids attacked by females with high 
270 lifetime expectancy $(19.8 \pm 2.48$; mean \pm SE) than those with intermediate ones $(5.88 \pm 1.1)$, whereas

271 both of them did not differ from females with low expected lifetime $(14.5 \pm 3.54)$.

\section{Effects of the mating status and the flower species on foraging behavior of female parasitoids}

\section{3 with intermediate expected lifetime.}

274 There was no significant interaction between mating status and flower species on foraging decisions

$275\left(\chi^{2}=2.32, \mathrm{df}=1, \mathrm{p}=0.13\right)$. However, mated females chose more frequently the host patch $(68 \pm 9.5 \% ; \pm$

276 SE) than the food patch $(32 \pm 9.5 \%)$ whereas unmated females chose preferentially the food patch $(92.9$

$277 \pm 4.8 \%)$ over the host one $\left(7.1 \pm 4.8 \%\right.$; chosen patch: $\chi^{2}=22.79, \mathrm{df}=1, \mathrm{p}<0.001 ;$ Fig 1-B $)$. Foraging

278 decisions were not affected by the flower species $\left(\chi^{2}=0.23, \mathrm{df}=1, \mathrm{p}=0.63\right)$. Whatever their mating status

279 and the flower species, females who chose the host patch tended to take more time to adopt a decision

280 than females who chose the food patch (latency before decision-making: $\chi^{2}=3.44, \mathrm{df}=1, \mathrm{p}=0.064 ; 5.95$

$281 \pm 1.04$ vs $3.49 \pm 0.73$ min respectively; mean $\pm \mathrm{SE}$ ). As only 2 out of 30 unmated females chose the

282 host patch and eight out of the 25 mated females tested chose the food patch, only the time residency

283 of unmated females on food patches (for which we had sufficient numbers) could be compared between

284 flower species. Time residency on the food patch did not vary according to the flower species $\left(\chi^{2}=1.16\right.$,

$285 \mathrm{df}=1, \mathrm{p}=0.28)$ and there was no difference in the number of feeding events between the two flower

$286 \operatorname{species}\left(\chi^{2}=2.32, \mathrm{df}=1, \mathrm{p}=0.13\right)$.

287 Mating and life expectancy effects on the flower preference of parasitoids

288 There was no significant interaction between life expectancy levels and mating status on flower species

289 preferred by females (flower chosen: $\chi^{2}=0.15, \mathrm{df}=1, \mathrm{p}=0.7$ ). Mustard flowers were largely preferred 290 over buckwheat ones by females (Fig 2$)$ whatever their mating status $\left(\chi^{2}=0.058, \mathrm{df}=1, \mathrm{p}=0.81\right)$ and 291 expected lifetime $\left(\chi^{2}=0.59, \mathrm{df}=1, \mathrm{p}=0.44\right)$. There was no difference in the time needed to make a 292 decision and patch time residency between mating status $\left(\chi^{2}=0.038, \mathrm{df}=1, \mathrm{p}=0.84\right.$ and $\chi^{2}=0.6, \mathrm{df}=1$, $293 \mathrm{p}=0.44$, respectively), life expectancy levels $\left(\chi^{2}=2.35, \mathrm{df}=1, \mathrm{p}=0.13\right.$ and $\chi^{2}=1.1, \mathrm{df}=1, \mathrm{p}=0.29$, 294 respectively) and chosen flower species $\left(\chi^{2}=0.14, \mathrm{df}=1, \mathrm{p}=0.71\right.$ and $\chi^{2}=0.13, \mathrm{df}=1, \mathrm{p}=0.71$, 295 respectively). However, there was a significant interaction between expected lifetime levels and the 
flower species chosen by parasitoids on on the number of times the wasp fed at the flower $\left(\chi^{2}=4.81\right.$,

$297 \mathrm{df}=1, \mathrm{p}<0.05)$. This results from the low number of females with an intermediate life expectancy that

298 chose buckwheat $(\mathrm{N}=4)$, with only one food intake for two of them $(0.50 \pm 0.29$ mean $\pm \mathrm{SE})$, but a high

299 number of females that chose mustard flowers $(\mathrm{N}=25)$ with a higher number of food acquisition events

300 per female $(1.67 \pm 0.60)$. Additionally, parasitoids with low life expectancy had significantly higher

301 numbers of times that they fed at buckwheat $(4.86 \pm 1.74)$ and mustard $(3.96 \pm 0.67)$ flowers than newly

302 emerged females with intermediate life expectancy.

\section{Discussion}

304 Our results partly confirmed the first hypothesis as, independently of flower species constituting the food patch, mated A. rhopalosiphi female parasitoids with the highest life expectancy levels (i.e. honeyfed females with high energetic levels) favored their immediate fitness by all choosing the host patch. However, although there was an increasing proportion of females that favored the food patch and then their future fitness, as their expected lifetime decreased, more than $50 \%$ of them still favored the host patch and immediate fitness gains. The second hypothesis was validated as females with intermediate expected lifetime that were mated favored their immediate reproduction, whereas unmated ones favored in a larger proportion to feed and thus future fitness gains, still independently of the flower species.

312 Finally, the third hypothesis was refuted as there was no interaction between their physiological status

313 and the flower species. However, under all physiological conditions, females preferred the flower

314 species that was the more attractive (mustard) rather than the flower species with the more suitable 315 nectar (buckwheat).

\section{Effects of expected lifetime on mated female parasitoids foraging decision-making}

317 Both SB and TSK (Sirot and Bernstein 1996; Tenhumberg et al. 2006) stochastic models predict that 318 fed female parasitoids are more prone to reproduce whereas starving ones should favor feeding. Such 319 results are also supported empirically for several parasitoid species such as Bathyplectes curculionis 320 (Hymenoptera, Ichneumonidae), Cotesia rubecula (Hymenoptera, Braconidae) (Wäckers 1994; Jacob 321 and Evans 2001) and Leptopilina heterotoma (Hymenoptera: Figitidae) (Roitberg et al., 1992). Our 
results partially confirmed this first hypothesis, as all honey-fed A. rhopalosiphi females tested (i.e.

323 with a high expected lifetime) always choose to reproduce and favored their immediate fitness.

324 However, only 20 to $45 \%$ of starved females (with low and intermediate life expectancies), chose to

325 feed in our study, which contrasts with expectations based on the SB or TSK models. In their study,

326 Siekmann et al., (2004) partially confirmed as well model predictions and demonstrated that only well-

327 fed female favored host foraging, whereas unfed females of Cotesia rubecula (Hymenoptera,

328 Braconidae) chose in similar proportions between hosts or food. The authors explained that it may

329 partially results from consequences of food deprivation on neural network and decreased cues

330 sensitivity of females' parasitoids, leading to a more random searching behavior. Our results are similar,

331 by alternatively may be explained as follows. Females with intermediate and low life expectancies

332 tested in our experiment still had upper energetic levels than the critical thresholds of remaining energy

333 defined by mathematical models. However some of the females initially assigned to the $24 \mathrm{~h}$ starvation

334 treatment (i.e. low life expectancy) were already dead before being tested, indicating that at least part

335 of the females were below those critical energetic levels.

336 More plausibly, these differences between the model predictions and our results imply that these

337 expectations may not apply to all parasitoid species and/or that some other important parameters or

338 assumptions should be considered. Firstly, it may depend on species involved in the plant-host-

339 parasitoid system considered. Prior studies were using parasitoid species that could find both flower

340 nectar and hosts on the same plant species under natural conditions (Wäckers 1994; Jacob and Evans

341 2001). Therefore, environmental cues used for decision-making by such parasitoids may derive from a

342 strong coevolution with the host plant, making them more prone to search for hosts and food at the same

343 time and same location. At the opposite, A. rhopalosiphi is a specialist of wheat aphids and consequently

344 do not encounter flower nectar and hosts on the same plants. Consequently, A. rhopalosiphi females

345 independently of their expected lifetime may have favored their immediate fitness instead of their future

346 one because of their inability to assess flower cues without prior feeding experiences. Another

347 explanation would be that other physiological factors such as the mating status affect the foraging

348 decisions. Indeed, in the second experiment (see next paragraph for results on unmated females), for 
349 the same level of expected lifetime and thus of energetic reserves, the contrast in decision-making

350 between mated and unmated females was strong. Consequently, mating most likely drives foraging

351 decisions either by modifying life expectancy perception, or by being a predominant factor on the

352 elaboration of their foraging strategy. The high predisposition of females of different expected lifetime

353 to reproduce may be the result of interacting intrinsic factors. Nevertheless, hierarchy in physiological

354 constraints acting on foraging decisions is not documented for any organisms. Further investigations

355 are thus needed to confirm how these physiological factors may interact and modified foraging

356 decisions in a broader range of organisms.

\section{Mating status effects on the foraging behavior of starved parasitoids}

358 There was a clear difference in foraging decisions between mated females who favored their

359 reproduction whereas unmated ones favored the food acquisition by choosing the flowering plant. In

360 the few studies focusing on the effect of the mating status on host foraging, mated females showed

361 higher reproductive predisposition than unmated ones (Michaud and Mackauer 1995; Kugimiya et al.

362 2010). This can be explained by the haplo-diploid sex determination of Hymenopteran species.

363 Unmated females lay non-fertilized eggs developing in males whereas mated females produce both

364 genders in their offspring. Thus, under the context of the local mate competition theory (Hamilton

365 1967), there is an evolutionary advantage for mated parasitoid females to favor their immediate fitness

366 and for unmated ones to favor their future fitness, by feeding until finding a mate to be able to produce

367 both genders. Among studies that have been focusing on the effect of mating status on host foraging

368 behavior, increased reproductive predisposition after mating has already been observed (Kugimiya et

369 al. 2010). For instance, under field conditions, Fauvergue et al. (2008) found that mated females of

370 Lysiphlebus testaceipes (Hymenoptera : Braconidae) increased their host patch exploitation (i.e.,

371 number of host attacks) according to the increase of host density contrary to unmated ones, whereas

372 patch residency times were similar for both mated and unmated individuals. In our study, we could not

373 compare host patch exploitation between females with different mating status, as they had highly

374 contrasted patch choices (host $v s$ food for mated and unmated respectively), which resulted into

375 multicollinearity among predictor variables and did not allow to properly performing statistical analysis. 
However, results showed that patch decisions were taken more quickly for females that chose the food

377 patches (majority of unmated females) compared to the ones that favored host patches (majority of mated females), which would be consistent with a higher predisposition for unmated females to favor their future fitness by feeding contrary to the mated ones.

\section{Flower species effects on female parasitoids foraging behavior}

381

382

383

384

385

386

387

388

389

390

391

392

393

Environmental factors play a major role on the foraging decisions between breeding and feeding in many animal species such as mammals (Bronikowski and Altmann 1996; Murray et al. 2006; Corlatti et al. 2013) and birds (Hennicke and Culik 2005; Harding et al. 2011) but remain poorly studied for insects (Rasa 1998). Surprisingly, it has been understudied in parasitoids and our study is the first one to test the impact of flower species on their foraging decisions between feeding and ovipositing. Contrary to our third hypothesis, flowering plant species did not interact with physiological conditions of A. rhopalosiphi females on their foraging decisions. Indeed, independently of the flower species, decision-making between host and food patches was only affected by physiological factors and was similar between flower species that composed the food patch. As mustard and buckwheat flowers have opposite nectar suitability and attractiveness, these flower characteristics may have concomitantly influenced the choice of A. rhopalosiphi females (i.e. attractiveness for mustard, nectar suitability for buckwheat), resulting in similar foraging choices for both flower species.

Although the flower species did not influence A. rhopalosiphi females foraging decisions between reproducing and feeding, our last experiment showed that they preferred mustard flower over buckwheat one, the latter having the most suitable nectar but being the least attractive, under all physiological conditions. Usually, flower attractiveness is assumed to be the most determinant factor of the foraging decisions of female parasitoids. Foti et al., (2017) suggested that female parasitoids might use volatile organic compounds of floral plants to localize food sources and assess their suitability. However, their capacity to evaluate nectar quality may depend on a direct contact as it is the case for the evaluation of the host quality (Godfray, 1994; van Baaren et al., 2009). Thus, preferences of $A$. rhopalosiphi for mustard flowers is most likely resulting from innate preference for yellow colors (Lucchetta, Bernstein, Théry et al., 2008; Wäckers, 1994), and/or for specific floral odors (Belz et al. 
404 (Battaglia et al. 1995) and innate odor recognition (Budenberg 1990) during host foraging.

405 As flower species did not affect decisions of A. rhopalosiphi females in any of the trials, it may be confidently assumed that it did not interact with their physiological internal state. Our results support the assumption that tested females were not able to assess nectar quality from a distance to make an optimal choice, and that they had to make decisions based on their innate preferences and their physiological state. Interestingly choosing buckwheat flowers, with the more suitable nectar, would

410 have been more beneficial for females that had favored future fitness gains by choosing nutritional

411 patches. As relationships between parasitoids and many potential nutritive flower species do not result

412 from a long-term adaptive coevolution such as with their hosts, variation in flower quality may mislead

413 parasitoids in their foraging decisions. When encountering flowers with opposite attractiveness and 414 profitability, inexperienced female parasitoids may face ecological traps by being attracted toward 415 plants with low energetic nectar rewards. Associative learning for odors (Takasu and Lewis 1996) and 416 visual cues (Lucchetta et al., 2008) relative to food was demonstrated for parasitoids species. Therefore, 417 feeding experiences of adult females (Lucchetta et al. 2008; Giunti et al. 2015) may help them to 418 optimize their foraging decisions (Siekmann et al. 2004), notably through the decrease of environmental 419 uncertainty as predicted by the information primacy hypothesis (Woodworth 1958; Inglis et al. 2001). 420 Indeed, it is interesting to note that food foraging behavior of parasitoid insects has never been extent 421 to this conceptual framework whereas it was done for birds (Giles et al. 2002) or bees (Katz and Naug 422 2015). This theoretical context would most likely bring complementary insights to the OFT approach 423 on parasitoids foraging behavior.

\section{Conclusion}

425 The tradeoff between immediate and future fitness gains is a key determinant in foraging decisions 426 taken by organisms. The complexity of such decisional processes has led to the use of dynamic modeling to disentangle how intrinsic and extrinsic factors of individuals may modify their optimal foraging strategies. However, our study showed that there is a need to test theory with empirical studies, to clarify assumptions made by modelers that may result in divergent output from theoretical 
predictions. According to our results for instance, reproductive status, such as the mating condition, has

been understudied and needs to be considered in future empirical and theoretical studies. Moreover, the

potential hierarchy between intrinsic factors and their interactions with environmental parameters

should be investigated to improve our understanding of foraging strategies adopted by these organisms.

434 Finally, results of this study highlight that new interactions between parasitoid insects and flowering

plants may constitute a challenge for developing environmental methods using plant diversity to

promote diversity and trophic system stability of pest natural enemies, such as parasitoids in biological

437

control programs.

\section{References}

Azzouz H, Giordanengo P, Wäckers FL, Kaiser L (2004) Effects of feeding frequency and sugar concentration on behavior and longevity of the adult aphid parasitoid: Aphidius ervi (Haliday) (Hymenoptera: Braconidae). Biological Control 31:445-452. doi: 10.1016/j.biocontrol.2004.07.013

Battaglia D, Pennacchio F, Romano A, Tranfaglia A (1995) The role of physical cues in the regulation of host recognition and acceptance behavior of Aphidius ervi Haliday (Hymenoptera: Braconidae). Journal of Insect Behavior 8:739-750. doi: 10.1007/BF02009503

Belz E, Kölliker M, Balmer O (2013) Olfactory attractiveness of flowering plants to the parasitoid Microplitis mediator: potential implications for biological control. BioControl 58:163-173. doi: 10.1007/s10526-012-9472-0

Bernstein C, Jervis M (2008) Food-searching in parasitoids: the dilemma of choosing between 'immediate'or future fitness gains. Behavioral ecology of insect parasitoids: from theoretical approaches to field applications 129-171

Bourdais D, Hance T (2009) Lack of behavioural evidence for kin avoidance in mate choice in a hymenopteran parasitoid (Hymenoptera: Braconidae). Behavioural Processes 81:9294. doi: 10.1016/j.beproc.2009.02.015

Bronikowski AM, Altmann J (1996) Foraging in a variable environment: weather patterns and the behavioral ecology of baboons. Behavioral Ecology and Sociobiology 39:11-25. doi: $10.1007 / \mathrm{s} 002650050262$

Budenberg WJ (1990) Honeydew as a contact kairomone for aphid parasitoids. Entomologia Experimentalis et Applicata 55:139-148. doi: 10.1111/j.1570-7458.1990.tb01357.x

Clark CW, Mangel M (2000) Dynamic state variable models in ecology: methods and applications. Oxford University Press, New York 
Corlatti L, Bassano B, Valencak TG, Lovari S (2013) Foraging strategies associated with alternative reproductive tactics in a large mammal: Foraging strategies of male chamois. Journal of Zoology 291:111-118. doi: 10.1111/jzo.12049

Damien M (2018) Favoriser les ennemis naturels de ravageurs par la diversité végétale dans un contexte hivernal. PhD Thesis, Rennes 1

Damien M, Le Lann C, Desneux N, et al (2017) Flowering cover crops in winter increase pest control but not trophic link diversity. Agriculture, Ecosystems \& Environment 247:418-425. doi: 10.1016/j.agee.2017.07.015

de Jong G, van Noordwijk AJ (1992) Acquisition and Allocation of Resources: Genetic (CO) Variances, Selection, and Life Histories. The American Naturalist 139:749-770. doi: $10.1086 / 285356$

Dedryver CA (1987) Biologie, écologie et dynamique de populations des pucerons des céréales en climat océanique. Paris 11

Fauvergue X, Fleury F, Lemaitre C, Allemand R (1999) Parasitoid Mating Structures When Hosts Are Patchily Distributed: Field and Laboratory Experiments with Leptopilina boulardi and L. heterotoma. Oikos 86:344. doi: 10.2307/3546451

Fauvergue X, Lo Genco A, Lo Pinto M (2008) Virgins in the wild: mating status affects the behavior of a parasitoid foraging in the field. Oecologia 156:913-920. doi: 10.1007/s00442-008-1037-7

Fink U, Völkl W (1995) The effect of abiotic factors on foraging and oviposition success of the aphid parasitoid, Aphidius rosae. Oecologia 103:371-378. doi: 10.1007/BF00328627

Fischbein D, Jofré N, Corley JC (2016) A comparative analysis of host feeding and life-history traits in parasitoid wasps. Entomologia Experimentalis et Applicata 159:172-180. doi: 10.1111/eea. 12422

Foti MC, Rostás M, Peri E, et al (2017) Chemical ecology meets conservation biological control: identifying plant volatiles as predictors of floral resource suitability for an egg parasitoid of stink bugs. Journal of Pest Science 90:299-310. doi: 10.1007/s 10340-0160758-3

Giles S, Inglis I, Van Driel K, et al (2002) Effect of hunger on starlings' preferences for food sources associated with variability or uncertainty. Behav 139:1223-1235. doi: $10.1163 / 15685390260437353$

Giunti G, Canale A, Messing RH, et al (2015) Parasitoid learning: Current knowledge and implications for biological control. Biological Control 90:208-219. doi: 10.1016/j.biocontrol.2015.06.007

Godfray HCJ (1994) Parasitoids: behavioral and evolutionary ecology. Princeton University Press, Princeton, N.J

Hamilton WD (1967) Extraordinary Sex Ratios. Science 156:477-488. doi: 10.1126/science.156.3774.477 
Harding AMA, Welcker J, Steen H, et al (2011) Adverse foraging conditions may impact body mass and survival of a high Arctic seabird. Oecologia 167:49-59. doi: 10.1007/s00442011-1971-7

Hartig F (2018) DHARMa: Residual Diagnostics for Hierarchical (Multi-Level / Mixed) Regression Models

Hassell MP, Southwood TRE (1978) Foraging Strategies of Insects. Annual Review of Ecology and Systematics 9:75-98. doi: 10.1146/annurev.es.09.110178.000451

Heimpel GE, Collier TR (1996) THE EVOLUTION OF HOST-FEEDING BEHAVIOUR IN INSECT PARASITOIDS. Biological Reviews 71:373-400. doi: 10.1111/j.1469185X.1996.tb01279.x

Hennicke J, Culik B (2005) Foraging performance and reproductive success of Humboldt penguins in relation to prey availability. Marine Ecology Progress Series 296:173-181. doi: $10.3354 /$ meps 296173

Hervé M (2013) SequenceR : une interface d'encodage de séquences comportementales.

\section{http://www.maximeherve.com/r-statistiques/sequencer}

Inglis IR, Langton S, Forkman B, Lazarus J (2001) An information primacy model of exploratory and foraging behaviour. Animal Behaviour 62:543-557. doi: 10.1006/anbe.2001.1780

Irvin NA, Pinckard TR, Perring TM, Hoddle MS (2014) Evaluating the potential of buckwheat and cahaba vetch as nectar producing cover crops for enhancing biological control of Homalodisca vitripennis in California vineyards. Biological Control 76:10-18. doi: 10.1016/j.biocontrol.2014.04.006

Jacob HS, Evans EW (2001) Influence of Food Deprivation on Foraging Decisions of the Parasitoid \&lt;I\&gt;Bathyplectes curculionis\&lt;/I\&gt; (Hymenoptera: Ichneumonidae). Annals of the Entomological Society of America 94:605-611. doi: 10.1603/0013-8746(2001)094[0605:IOFDOF]2.0.CO;2

Jervis MA, Kidd NAC, Fitton MG, et al (1993) Flower-visiting by hymenopteran parasitoids. Journal of Natural History 27:67-105. doi: 10.1080/00222939300770051

Kant R, Minor M, Trewick S (2012) Mating or ovipositing? A crucial decision in the life history of the cabbage aphid parasitoid Diaeretiella rapae (M'Intosh). Ecological Entomology 37:169-174. doi: 10.1111/j.1365-2311.2012.01347.x

Katz K, Naug D (2015) Energetic state regulates the exploration-exploitation trade-off in honeybees. BEHECO 26:1045-1050. doi: 10.1093/beheco/arv045

Killen SS, Marras S, Metcalfe NB, et al (2013) Environmental stressors alter relationships between physiology and behaviour. Trends in Ecology \& Evolution 28:651-658. doi: 10.1016/j.tree.2013.05.005

Kugimiya S, Uefune M, Shimoda T, Takabayashi J (2010) Orientation of the parasitic wasp, Cotesia vestalis (Haliday) (Hymenoptera: Braconidae), to visual and olfactory cues of 

Entomology and Zoology 45:369-375. doi: 10.1303/aez.2010.369

542

543

544

545

546

547

548

549

550

551

552

553

554

555

556

557

558

559

560

561

562

Lacher Thomas E, Willig MR, Mares MA (1982) Food Preference as a Function of Resource Abundance with Multiple Prey Types: An Experimental Analysis of Optimal Foraging Theory. The American Naturalist 120:297-316. doi: 10.1086/283992

Le Lann C (2009) Partage de la ressource au sein d'une guilde: des histoires de vie, comportements et réactions à la température contrastés. PhD Thesis

Le Lann C, Outreman Y, van Alphen JJM, van Baaren J (2011a) First in, last out: asymmetric competition influences patch exploitation of a parasitoid. Behavioral Ecology 22:101107. doi: $10.1093 /$ beheco/arq 180

Le Lann C, Roux O, Serain N, et al (2011b) Thermal tolerance of sympatric hymenopteran parasitoid species: does it match seasonal activity? Physiological Entomology 36:2128. doi: 10.1111/j.1365-3032.2010.00758.x

Le Lann C, Wardziak T, van Baaren J, van Alphen JJM (2011c) Thermal plasticity of metabolic rates linked to life-history traits and foraging behaviour in a parasitic wasp: Temperature affects physiology and behaviour of a parasitoid. Functional Ecology 25:641-651. doi: 10.1111/j.1365-2435.2010.01813.x

Lee JC, Andow DA, Heimpel GE (2006) Influence of floral resources on sugar feeding and nutrient dynamics of a parasitoid in the field. Ecological Entomology 31:470-480. doi: 10.1111/j.1365-2311.2006.00800.x

Lee JC, Heimpel GE, Leibee GL (2004) Comparing floral nectar and aphid honeydew diets on the longevity and nutrient levels of a parasitoid wasp. Entomologia Experimentalis et Applicata 111:189-199. doi: 10.1111/j.0013-8703.2004.00165.x

Levie A, Vernon P, Hance T (2005) Consequences of Acclimation on Survival and Reproductive Capacities of Cold-Stored Mummies of $\langle\mathrm{I}\rangle$ Aphidius rhopalosiphi</I $\rangle$ (Hymenoptera: Aphidiinae). Journal of Economic Entomology 98:704-708. doi: 10.1603/0022-0493-98.3.704

Lucchetta P, Bernstein C, Théry M, et al (2008) Foraging and associative learning of visual signals in a parasitic wasp. Animal Cognition 11:525-533. doi: 10.1007/s10071-008$0144-5$

Lucchetta P, Desouhant E, Wajnberg E, Bernstein C (2007) Small but smart: the interaction between environmental cues and internal state modulates host-patch exploitation in a parasitic wasp. Behavioral Ecology and Sociobiology 61:1409-1418

Martinou AF, Milonas PG, Wright DJ (2009) Patch residence decisions made by Aphidius colemani in the presence of a facultative predator. Biological Control 49:234-238. doi: 10.1016/j.biocontrol.2009.03.004

McClure M, Whistlecraft J, McNeil JN (2007) Courtship Behavior in Relation to the Female Sex Pheromone in the Parasitoid, Aphidius ervi (Hymenoptera: Braconidae). Journal of Chemical Ecology 33:1946-1959. doi: 10.1007/s10886-007-9355-5 
Michaud J-P, Mackauer M (1995) Oviposition Behavior of Monoctonus paulensis (Hymenoptera: Aphidiidae): Factors Influencing Reproductive Allocation to Hosts and Host Patches. Annals of the Entomological Society of America 88:220-226. doi: 10.1093/aesa/88.2.220

Minkenberg OPJM, Tatar M, Rosenheim JA (1992) Egg Load as a Major Source of Variability in Insect Foraging and Oviposition Behavior. Oikos 65:134. doi: 10.2307/3544896

Morano S, Stewart KM, Sedinger JS, et al (2013) Life-history strategies of North American elk: trade-offs associated with reproduction and survival. Journal of Mammalogy 94:162-172. doi: 10.1644/12-MAMM-A-074.1

Murray CM, Eberly LE, Pusey AE (2006) Foraging strategies as a function of season and rank among wild female chimpanzees (Pan troglodytes). Behavioral Ecology 17:1020-1028. doi: 10.1093/beheco/arl042

Outreman Y, Le Ralec A, Wajnberg E, Pierre J-S (2005) Effects of within- and among-patch experiences on the patch-leaving decision rules in an insect parasitoid. Behavioral Ecology and Sociobiology 58:208-217. doi: 10.1007/s00265-004-0895-1

Pyke GH (1984) Optimal Foraging Theory: A Critical Review. Annual Review of Ecology and Systematics 15:523-575. doi: 10.1146/annurev.es.15.110184.002515

Rasa OAE (1998) Biparental investment and reproductive success in a subsocial desert beetle: the role of maternal effort. Behavioral Ecology and Sociobiology 43:105-113. doi: $10.1007 / \mathrm{s} 002650050472$

Reaney LT (2007) Foraging and mating opportunities influence refuge use in the fiddler crab, Uca mjoebergi. Animal Behaviour 73:711-716. doi: 10.1016/j.anbehav.2006.05.022

Roff DADA (2002) Life history evolution

Roitberg BD, Mangel M, Lalonde RG, et al (1992) Seasonal dynamic shifts in patch exploitation by parasitic wasps. Behavioral Ecology 3:156-165. doi: 10.1093/beheco/3.2.156

Russell M (2015) A meta-analysis of physiological and behavioral responses of parasitoid wasps to flowers of individual plant species. Biological Control 82:96-103. doi: 10.1016/j.biocontrol.2014.11.014

Siekmann G, Keller MA, Tenhumberg B (2004) The Sweet Tooth of Adult Parasitoid Cotesia rubecula: Ignoring Hosts for Nectar? Journal of Insect Behavior 17:459-476. doi: 10.1023/B:JOIR.0000042535.76279.c7

Sirot E, Bernstein C (1996) Time sharing between host searching and food searching in parasitoids: state-dependent optimal strategies. Behavioral Ecology 7:189-194. doi: 10.1093/beheco/7.2.189

Snart CJP, Kapranas A, Williams H, et al (2018) Sustenance and Performance: Nutritional Reserves, Longevity, and Contest Outcomes of Fed and Starved Adult Parasitoid Wasps. Frontiers in Ecology and Evolution 6:. doi: 10.3389/fevo.2018.00012 
Stearns SC (1976) Life-History Tactics: A Review of the Ideas. The Quarterly Review of Biology 51:3-47

Stienen EWM, Brenninkmeijer A, Courtens W (2015) Intra-specific plasticity in parental investment in a long-lived single-prey loader. Journal of Ornithology 156:699-710. doi: $10.1007 / \mathrm{s} 10336-015-1170-0$

Takasu K, Lewis WJ (1996) The role of learning in adult food location by the larval parasitoid,Microplitis croceipes (Hymenoptera: Braconidae). Journal of Insect Behavior 9:265-281. doi: 10.1007/BF02213870

Tatar M, Carey JR (1995) Nutrition Mediates Reproductive Trade-Offs with Age-Specific Mortality in the Beetle Callosobruchus Maculatus. Ecology 76:2066-2073. doi: $10.2307 / 1941681$

Tena A, Pekas A, Cano D, et al (2015) Sugar provisioning maximizes the biocontrol service of parasitoids. Journal of Applied Ecology 52:795-804. doi: 10.1111/1365-2664.12426

Tena A, Senft M, Desneux N, et al (2018) The influence of aphid-produced honeydew on parasitoid fitness and nutritional state: A comparative study. Basic and Applied Ecology 29:55-68. doi: 10.1016/j.baae.2018.04.003

Tenhumberg B, Siekmann G, Keller MA (2006) Optimal time allocation in parasitic wasps searching for hosts and food. Oikos 113:121-131. doi: 10.1111/j.00301299.2006.14274.x

Tompkins J-ML, Wratten SD, Wäckers FL (2010) Nectar to improve parasitoid fitness in biological control: Does the sucrose:hexose ratio matter? Basic and Applied Ecology 11:264-271. doi: 10.1016/j.baae.2009.12.010

Török J, Hegyi G, Tóth L, Könczey R (2004) Unpredictable food supply modifies costs of reproduction and hampers individual optimization. Oecologia 141:432-443. doi: $10.1007 / \mathrm{s} 00442-004-1667-3$

Townsend CR, Hildrew AG (1980) Foraging in a patchy environment by a predatory netspinning caddis larva: A test of optimal foraging theory. Oecologia 47:219-221. doi: 10.1007/BF00346824

Van Alphen JJM, Vet LEM (1986) An evolutionary approach to host finding and selection.

van Baaren J, Le Lann C, Pichenot J, et al (2009) How could host discrimination abilities influence the structure of a parasitoid community? Bulletin of Entomological Research 99:299. doi: 10.1017/S0007485308006342

van Baaren J, Outreman Y, Boivin G (2005) Effect of low temperature exposure on oviposition behaviour and patch exploitation strategy in parasitic wasps. Animal Behaviour 70:153-163. doi: 10.1016/j.anbehav.2004.10.016

Vattala HD, Wratten SD, Phillips CB, Wäckers FL (2006) The influence of flower morphology and nectar quality on the longevity of a parasitoid biological control agent. Biological Control 39:179-185. doi: 10.1016/j.biocontrol.2006.06.003 
662

663

664

665

666

667

668

669

670

671

672

673

674

675

676

677

678

679

680

681

682

683

684

685

686

Vollhardt IMG, Bianchi FJJA, Wäckers FL, et al (2010) Nectar vs. honeydew feeding by aphid parasitoids: does it pay to have a discriminating palate?: Does preference for nectar matter? Entomologia Experimentalis et Applicata 137:1-10. doi: 10.1111/j.15707458.2010.01025.x

Wäckers FL (1994) The effect of food deprivation on the innate visual and olfactory preferences in the parasitoid Cotesia rubecula. Journal of Insect Physiology 40:641649. doi: 10.1016/0022-1910(94)90091-4

Wajnberg É (2006) Time allocation strategies in insect parasitoids: from ultimate predictions to proximate behavioral mechanisms. Behavioral Ecology and Sociobiology 60:589611. doi: 10.1007/s00265-006-0198-9

Wajnberg E, Fauvergue X, Pons O (2000) Patch leaving decision rules and the Marginal Value Theorem: an experimental analysis and a simulation model. Behavioral Ecology 11:577-586. doi: 10.1093/beheco/11.6.577

Wang XG, Keller MA (2005) Patch Time Allocation by the Parasitoid Diadegma semiclausum (Hymenoptera: Ichneumonidae). II. Effects of Host Density and Distribution. Journal of Insect Behavior 18:171-186. doi: 10.1007/s10905-005-0473-z

Werren JH, Loehlin DW (2009) The Parasitoid Wasp Nasonia: An Emerging Model System with Haploid Male Genetics. Cold Spring Harbor Protocols 2009:pdb.emo134pdb.emo134. doi: 10.1101/pdb.emo134

Wexler Y, Wertheimer K-O, Subach A, et al (2017) Mating alters the link between movement activity and pattern in the red flour beetle: The effects of mating on behaviour. Physiol Entomol 42:299-306. doi: 10.1111/phen.12195

Winkler K, WäCkers F, Pinto DM (2009) Nectar-providing plants enhance the energetic state of herbivores as well as their parasitoids under field conditions. Ecological Entomology 34:221-227. doi: 10.1111/j.1365-2311.2008.01059.x

Wolf M, van Doorn GS, Leimar O, Weissing FJ (2007) Life-history trade-offs favour the evolution of animal personalities. Nature 447:581-584. doi: 10.1038/nature05835

Woodworth RS (1958) Dynamics of behavior.

Zuur AF, Ieno EN, Walker N, et al (2009) Mixed effects models and extensions in ecology with R. Springer New York, New York, NY 


\section{Figure legends}

688

689 Fig1-(A) Proportion of mated females with (a) low $(\mathrm{N}=18)$, (b) intermediate $(\mathrm{N}=25)$ and (c) high $690(\mathrm{~N}=25)$ expected lifetimes, choosing between the host patch (black bars) and the food patch (i.e. 691 mustard or buckwheat flowers) (grey bars). 1-(B) Proportion of (a) mated ( $\mathrm{N}=25)$ and (b) unmated 692 ( $\mathrm{N}=28)$ parasitoid females with intermediate expected lifetime, choosing between the host patch 693 (black bars) and the food patch (i.e. mustard or buckwheat flowers) (grey bars).

694

695 Fig2 Proportion of (a) mated parasitoid females with intermediate $(\mathrm{N}=13)$ and low $(\mathrm{N}=16)$ life 696 expectancy levels and (b) unmated ones with intermediate $(\mathrm{N}=15)$ and low $(\mathrm{N}=16)$ life expectancy

697 levels, choosing between the mustard (Sinapsis alba) and the buckwheat (Fagopyrum escalutum) flowers. 
(A) Mated females with different life expectancy levels

$\square$ Food patch $\quad$ Host patch

(a) Mated and Low

(b) Mated and Intermediate
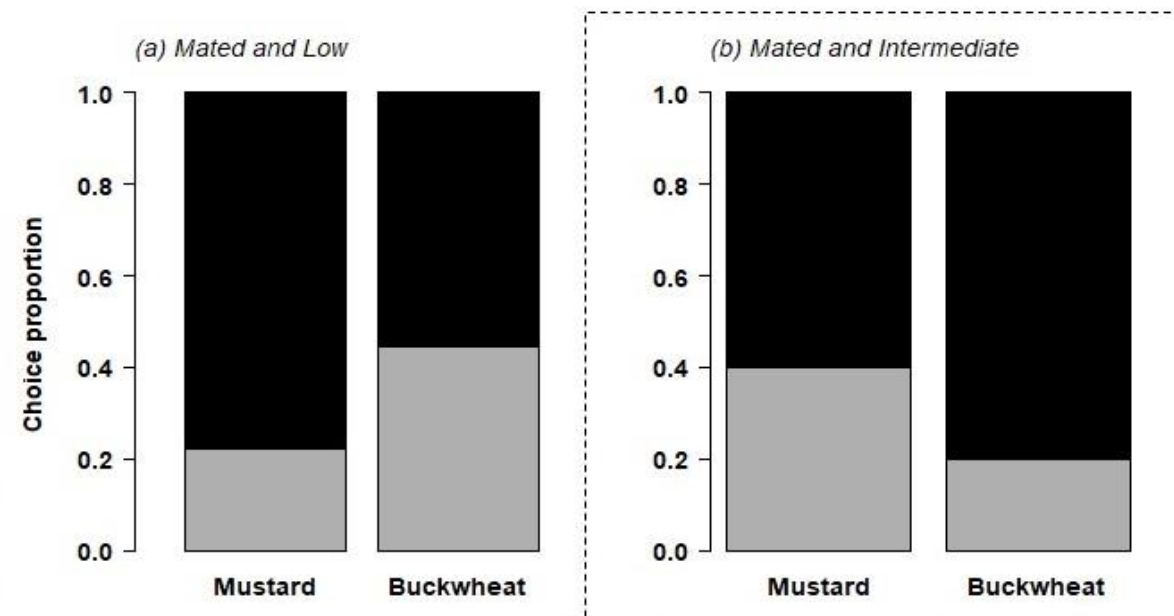

(c) Mated and High
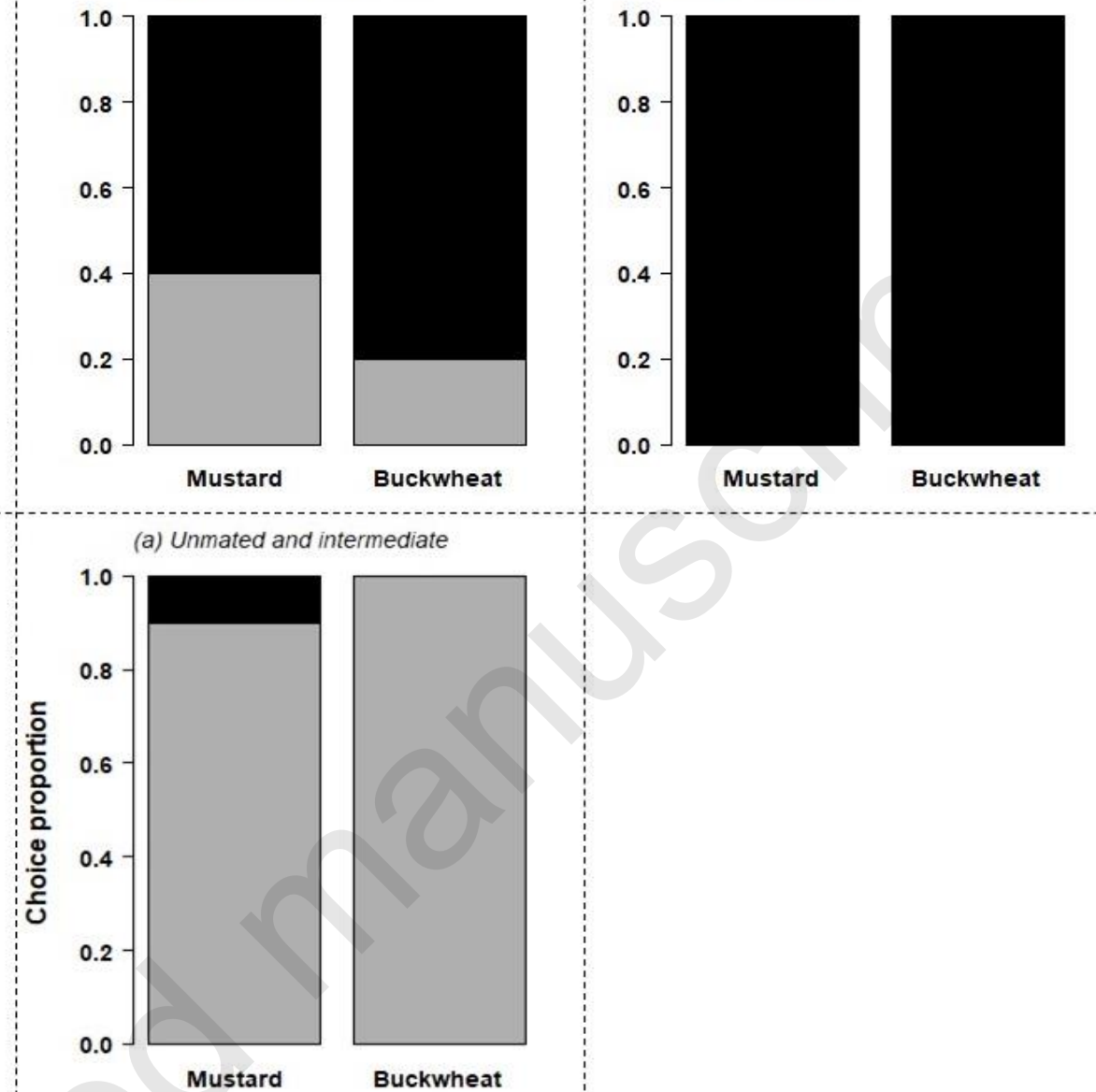

(B) Females with intermediate expected lifetime and different mating statuses

698

699 Fig1-A Proportion of mated females with (a) low $(\mathrm{N}=18)$, (b) intermediate $(\mathrm{N}=25)$ and (c) high ( $\mathrm{N}$

$700=25$ ) expected lifetimes, choosing between the host patch (black bars) and the food patch (i.e. mustard

701 or buckwheat flowers) (grey bars). 1-B Proportion of (a) mated $(\mathrm{N}=25)$ and $(\mathbf{b})$ unmated $(\mathrm{N}=28)$

702 parasitoid females with intermediate expected lifetime, choosing between the host patch (black bars)

703 and the food patch (i.e. mustard or buckwheat flowers) (grey bars). 
$\square$ Mustard $\square$ Buckwheat

(a) Mated

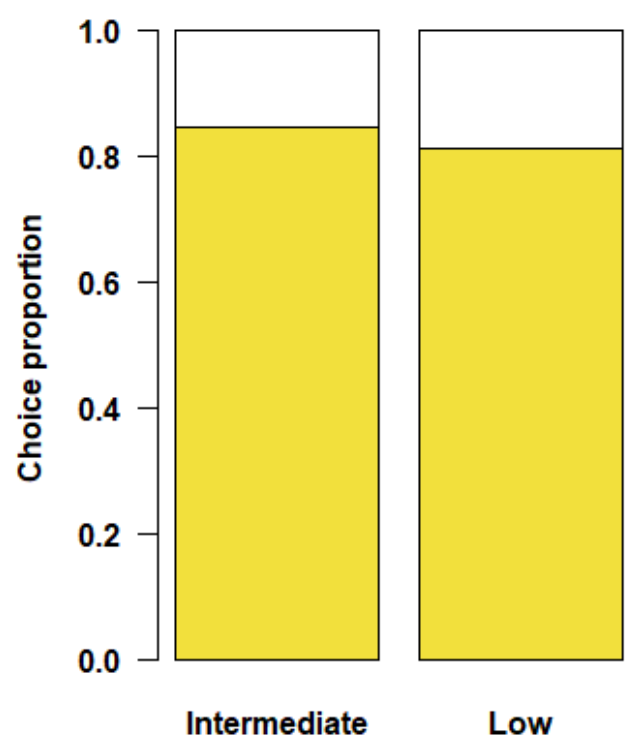

(b) Unmated

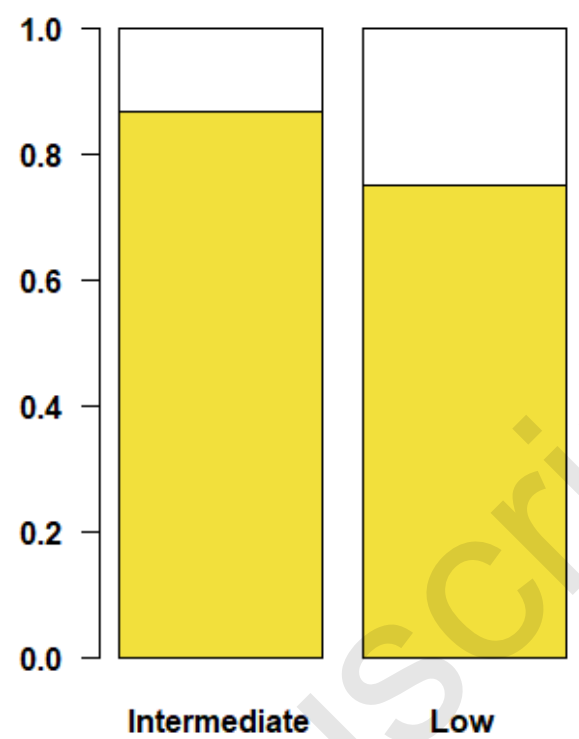

706

707 Fig2 Proportion of (a) mated parasitoid females with intermediate $(\mathrm{N}=13)$ and low $(\mathrm{N}=16)$ life

708 expectancy levels and $(\mathbf{b})$ unmated ones with intermediate $(\mathrm{N}=15)$ and low $(\mathrm{N}=16)$ life expectancy

709 levels, choosing between the mustard (Sinapsis alba) and the buckwheat (Fagopyrum escalutum) flowers. 